\title{
Produção de capins cultivados sob pastejo em diferentes lâminas de irrigação e estações anuais
}

\author{
Carlos A. B. de Alencar ${ }^{1}$, Rubens A. de Oliveira ${ }^{1}$, Antônio C. Cóser ${ }^{3}$, \\ Carlos E. Martins ${ }^{3}$, Fernando F. da Cunha ${ }^{1} \&$ José L. A. Figueiredo ${ }^{2}$
}

\begin{abstract}
RESUMO
Objetivou-se, com o presente trabalho, avaliar a produtividade de matéria seca de seis gramíneas, sob efeito de diferentes lâminas de irrigação, em diferentes estações do ano. O experimento foi conduzido em esquema de parcelas subsubdivididas havendo, nas parcelas seis gramíneas (Xaraés, Mombaça, Tanzânia, Pioneiro, Marandu e Estrela), nas subparcelas, seis lâminas de irrigação $(0,18,45,77,100$ e 120\% da referência) e, nas subsubparcelas, as estações (outono/ inverno e primavera/verão) no delineamento inteiramente casualizado, com duas repetições. Para diferenciar a aplicação das lâminas de irrigação, utilizou-se o sistema por aspersão em linha. O efeito proporcionado pelas diferentes gramíneas na produtividade de matéria seca dependeu da lâmina de irrigação e da estação do ano. De forma geral, a estação primavera/verão, em virtude de apresentar maior temperatura, proporcionou também maior produtividade em relação à estação outono/inverno. As lâminas de irrigação foram dependentes da estação para conferir efeito, ensejando maior produtividade apenas na estação outono/inverno. O capim-xaraés possui maior produtividade de matéria seca.
\end{abstract}

Palavras-chave: B. brizantha, P. maximum, P. purpureum, C. nlemfuensis, sistema em aspersão em linha

\section{Production of pasture grasses cultivated under grazing in different irrigation depths and seasons}

\begin{abstract}
This study aimed at evaluating the dry matter yield of six grasses under different irrigation depths and seasons. The experiment was conducted in a completely randomized design with two replications, in split-split plots. Six grasses (Xaraes, Mombaça, Tanzania, Pioneiro, Marandu and Estrela) constituted the plots, the irrigation depths $(0,18,45,77,100$ and $120 \%$ of the reference evapotranspiration) corresponded to the split-plots, and seasons (autumn/winter and spring/summer) the split-split-plots. A line source sprinkler system was used to vary the application of different depths of irrigation. The dry-matter yield of different grasses was dependent on irrigation depth and season. In general, the spring/summer season, because of higher temperatures, resulted in higher yields in relation to the autumn/winter season. The irrigation depths were dependent on the season, proportioning higher yields only in the autumn/winter season. The Xaraés-grass possesses greater productivity of dry matter.
\end{abstract}

Key words: B. brizantha, P. maximum, P. purpureum, C. nlemfuensis, line source sprinkler system

\footnotetext{
1 DEA/UFV. Av. Peter Henry Rolfs s/n, CEP 36570-000, Viçosa, MG. Fone: (31) 3899-1909. E-mail(s): c.brasileiro@yahoo.com.br; rubens@ufv.br; fcunha@vicosa.ufv.br 2 FAAG/UNIVALE. Rua Israel Pinheiro 2000, CEP 35020-220, Governador Valadares, MG. Fone: (33) 3279-5995. E-mail(s): joseluis@univale.br

${ }^{3}$ CNPGL/EMBRAPA. Rua Eugênio do Nascimento 610, CEP 36038-330, Juiz de Fora, MG. Fone: (32) 3249-4870. E-mail: acoser@cnpgl.embrapa.br; caeuma@cnpgl.embrapa.br
} 


\section{INTRODUÇÃO}

Devido ao baixo custo de produção em relação aos concentrados, as pastagens representam a forma mais prática e econômica de alimentação de bovinos (Cunha et al., 2007; Fernandes et al., 2003) ante o que grande parte da carne e do leite produzidos no país, advém de rebanhos mantidos a pasto.

O processo de intensificação da produção de leite e de carne bovina, implica em uso de forrageiras com alta capacidade de produção de matéria seca, destacando-se as cultivares dos gêneros Pennisetum, Cynodon, Panicum e Brachiaria, em razão seu elevado potencial produtivo e da sua qualidade. A região Leste do Estado de Minas Gerais apresenta grande potencial para o uso dessas forrageiras; entretanto, informações disponíveis sobre essas gramíneas, como o manejo da irrigação, são, ainda, pouco conhecidas.

As irregularidades do regime pluvial se tornam uma restrição ao desenvolvimento de plantas forrageiras, haja vista que, embora dentro de estações chuvosas, se observa períodos de déficit hídrico, pois a evapotranspiração da pastagem geralmente excede a precipitação pluvial (Cunha et al., 2007). O manejo da irrigação é um recurso para racionalizar a aplicação de água às culturas, de maneira complementar às precipitações pluviais, necessitando-se de procedimentos técnicos para determinação do turno de rega e da quantidade de água a ser aplicada (Rassini, 2001); desta for ma, a reposição de água ao solo por meio da irrigação, na quantidade adequada e no momento oportuno, é decisiva para o sucesso da intensificação da produção.

Com o uso da irrigação, o fator água deixa de ser o mais limitante para o crescimento das forrageiras, de modo que a estacionalidade de produção passa a depender da disponibilidade de nutrientes e da aeração do solo, do potencial genético da planta, da radiação solar e da temperatura. Em locais de maior latitude e altitude, onde ocorrem quedas mais acentuadas das temperaturas durante o inverno, não se deve esperar que a irrigação seja capaz de equacionar totalmente o problema da estacionalidade de produção, porém o período de utilização de uma pastagem pode ser aumentado com a prática da irrigação estratégica, que consiste em irrigar a pastagem nas interfaces das estações, quando há luminosidade e temperatura adequadas ao crescimento da planta forrageira.

Palieraqui et al. (2006) trabalhando com os capins Mombaça e Napier, observaram que a irrigação, além de aumentar a disponibilidade de ambas as forrageiras, aumentou o consumo de matéria seca pelos animais em condições de pastejo rotacionado. Teodoro et al. (2002) notaram que o capim-tanzânia respondeu satisfatoriamente à irrigação, aumentando a produtividade da matéria seca e sua composi- ção química, em relação à média geral anual de pastagens não irrigadas na região em que foi realizado o estudo. Mistura et al. (2006) também constataram o mesmo pois, avaliando a disponibilidade e a qualidade do capim-elefante com e sem irrigação adubado com nitrogênio e potássio, viram que o tratamento irrigado ensejou maiores produtividades de matéria seca total e lâminas foliares na matéria seca. Goh \& Bruce (2005) relatam que em Nova Zelândia pastos com Lolium perenne L. e Trifolium repens L., possuem, em geral, baixa produtividade ou morrem no período seco. Os mesmos autores avaliaram essas gramíneas forrageiras sob irrigação e observaram que, além da eliminação da mortalidade, a produtividade de matéria seca duplicou em relação ao tratamento não irrigado.

Propôs-se, com este trabalho, avaliar a produtividade de matéria seca de seis gramíneas forrageiras tropicais, em condições de pastejo no leste mineiro, sob diferentes lâminas de irrigação e estações do ano.

\section{MATERIAL E MÉTODOS}

Este trabalho foi conduzido de maio de 2003 a abril de 2005 e realizado na Universidade Vale do Rio Doce, localizado no município de Governador V aladares, MG, cujas coordenadas geográficas foram $18^{\circ} 47^{\prime} 30^{\prime}$ ' de latitude sul e $41^{\circ}$ 59' 04" de longitude oeste e altitude de $223 \mathrm{~m}$.

As médias de precipitação e evapotranspiração potencial de referência durante os dois anos de experimento, foram de $1.064 \mathrm{~mm}$ e $1.277 \mathrm{~mm}$, respectivamente. O solo na área experimental foi classificado como Cambissolo eutrófico, textura média. Fez-se a análise química para este solo ( $\mathrm{T}$ abela 1) e se corrigiu a acidez, seguindo-se recomendações da CFSEMG (1999). A adubação de plantio consistiu em $100 \mathrm{~kg} \mathrm{ha}^{-1}$ de $\mathrm{P}_{2} \mathrm{O}_{5}$, cuja fonte foi superfosfato simples, sendo aplicado todo o fósforo no fundo do sulco. A adubação total consistiu de $50 \mathrm{~kg} \mathrm{ha}^{-1}$ ano $^{-1}$ de $\mathrm{P}_{2} \mathrm{O}_{5}, 150 \mathrm{~kg} \mathrm{ha}^{-1}$ ano $^{-1}$ de $\mathrm{K}_{2} \mathrm{O}$ e $300 \mathrm{~kg} \mathrm{ha}^{-1} \mathrm{ano}^{-1}$ de $\mathrm{N}$, tendo como fontes o superfosfato simples, o cloreto de potássio e a uréia, respectivamente, sendo aplicado todo o fósforo em cobertura, a cada ano. O cloreto de potássio e a uréia foram aplicados em cobertura parcelada em 6 vezes ao ano, até o final da condução do experimento.

A distribuição granulométrica e os resultados das análises físico-hídricas do solo na camada de 0-30 cm, foram os seguintes: ar gila $=30 \%$; silte $=25 \%$; areia $=45 \%$; capacidade de campo $=0,30 \mathrm{~g} \mathrm{~g}^{-1}$; ponto de murcha $=0,17 \mathrm{~g} \mathrm{~g}^{-1}$ e densidade do solo $=1,38 \mathrm{~g} \mathrm{~cm}^{-3}$. Determinou-se a densidade do solo pelo método do anel volumétrico, descrito por EMBRAPA (1997) e os níveis de umidade do solo na capacidade de campo e no ponto de murcha permanente foram

Tabela 1. Características químicas do solo em amostras da área experimental, nas camadas de $0-30$ e $30-60 \mathrm{~cm}$

\begin{tabular}{|c|c|c|c|c|c|c|c|c|c|}
\hline \multirow{2}{*}{$\begin{array}{c}\text { Camada } \\
\text { cm }\end{array}$} & \multirow{2}{*}{$\mathrm{pH} \mathrm{H}_{2} \mathrm{O}$} & \multirow{2}{*}{$\mathrm{g} \mathrm{dm}^{\mathrm{M} .0}$} & $\mathbf{P}$ & $\mathrm{K}^{+}$ & $\mathrm{Ca}^{+2}$ & $\mathrm{Mg}^{+2}$ & $\mathrm{Al}^{+3}$ & $\mathrm{H}+\mathrm{Al}$ & \multirow{2}{*}{$\begin{array}{l}\mathbf{V} \\
\%\end{array}$} \\
\hline & & & \multicolumn{2}{|c|}{$\mathrm{mg} \mathrm{dm}^{-3}$} & \multicolumn{4}{|c|}{$\mathrm{cmol}_{\mathrm{c}} \mathrm{dm}^{-3}$} & \\
\hline $0-30$ & 6,5 & 1,6 & 6,0 & 60,0 & 3,8 & 1,0 & 0,1 & 4,0 & 55,0 \\
\hline $30-60$ & 6,3 & 0,3 & 5,2 & 17,0 & 2,4 & 0,8 & 0,1 & 4,3 & 43,0 \\
\hline
\end{tabular}


definidos para as tensões de 10 e $1.500 \mathrm{kPa}$, respectivamente. Os valores de retenção de água no solo foram determinados utilizando-se o método da Câmara de Richards (Richards, 1949).

O experimento foi conduzido em esquema de parcelas subsubdivididas, tendo nas parcelas as gramíneas ( Brachiaria brizantha cv. Xaraés, Panicum maximum cv. Mombaça, Panicum maximum cv. Tanzânia, Pennisetum purpureum cv. Pioneiro, Brachiaria brizantha cv. Marandu e Cynodon nlemfuensis L. cv. Estrela), nas subparcelas as lâminas de irrigação $\left(0,101,252,431,560\right.$ e $672 \mathrm{~mm} \mathrm{ano}^{-1}$, correspondendo a $0,18,45,77,100$ e $120 \%$ da referência, respectivamente) e nas subsubparcelas, as estações do ano (a estação outono/ inverno compreendeu os meses de abril a setembro e a estação primavera/verão, os meses de outubro a março) no delineamento inteiramente casualizado, com duas repetições.

As parcelas experimentais tinham $6 \mathrm{~m}$ de lar gura e $18 \mathrm{~m}$ de comprimento. As parcelas foram subdivididas em seis partes iguais, resultando em subparcelas de $6 \times 3 \mathrm{~m}\left(18 \mathrm{~m}^{2}\right)$. As lâminas de água se originaram das diferentes distribuições de água na direção perpendicular à tubulação com os aspersores; para isto se utilizou o sistema de irrigação por aspersão com distribuição dos aspersores em linha (Line Source Sprinkler System), conforme Hanks et al. (1976). Determinou-se a lâmina de irrigação de referência (100\%) por meio do monitoramento do potencial de água no solo, feita por tensiômetro digital instalado a 15 e $45 \mathrm{~cm}$ de profundidade. As irrigações foram efetuadas quando os tensiômetros instalados a $15 \mathrm{~cm}$, registraram valores de potencial matricial em torno de -60 kPa. A lâmina de irrigação aplicada foi medida com pluviômetros instalados em cada subparcela experimental e calculada por meio da Eq. 1.

$$
\mathrm{L}=\frac{(\mathrm{CC}-\theta)}{10} \mathrm{D} \mathrm{Z} \frac{1}{\mathrm{Ea}}
$$

em que:

$$
\begin{aligned}
& \text { L - lâmina total necessária, mm } \\
& \mathrm{CC} \text { - capacidade de campo, \% em peso } \\
& \theta \text { - teor de água do solo, no potencial matricial de } \\
& -60 \mathrm{kPa}, \% \text { em peso } \\
& \mathrm{D} \text { - densidade do solo, } \mathrm{g} \mathrm{\textrm {cm } ^ { - 3 }} \\
& \mathrm{Z} \text { - profundidade efetiva do sistema radicular, } \mathrm{cm} \\
& \text { Ea - eficiência de aplicação de água, decimal }
\end{aligned}
$$

Simultaneamente ao monitoramento da umidade do solo via tensiometria, dados meteorológicos diários foram coletados a partir de uma estação meteorológica automática, instalada dentro da área experimental.

O experimento foi conduzido sob manejo de pastejo; aos 45 dias após o corte de uniformização realizou-se o primeiro pastejo monitorado nas subparcelas, de maneira que o resíduo remanescente pós-pastejo apresentasse em torno de $15 \%$ de folhas verdes remanescentes, conforme Aroeira et al. (1999). Adotou-se o mesmo procedimento nas demais coletas e nos pastejos seguintes, porém com intervalo de 30 dias até o término do experimento. Os animais foram utilizados apenas como "ferramenta de corte" após a amostragem de cada gramínea, de maneira que a forragem disponível fosse consumida.
Realizou-se manualmente, antes da entrada dos animais, em área delimitada por uma unidade amostral metálica, de forma retangular e com o tamanho de 1,0 x 0,5 m (área útil de $0,5 \mathrm{~m}^{2}$ ), a coleta sistemática das amostras. A unidade amostral foi posicionada em locais predeterminados, evitando-se coletar amostras sucessivas nas mesmas áreas. Toda a massa verde colhida foi acondicionada em sacos plásticos, devidamente identificados e imediatamente pesada; em seguida se retirou uma subamostra, novamente pesada, acondicionada em saco de papel identificado e posta a secar em estufa com circulação de ar a $60^{\circ} \mathrm{C}$, pelo tempo de $72 \mathrm{~h}$; após a secagem, as subamostras foram pesadas novamente para obtenção da produtividade de MS, passível de ser consumida pelos animais.

Para a realização da análise estatística utilizou-se a média dos valores obtidos durante os dois anos do experimento, nas estações outono/inverno e primavera/verão. Os dados foram submetidos às análises de variância e de regressão. A comparação de médias foi realizada usando-se o teste de Tukey a 5\% de probabilidade. Escolheram-se, para o fator quantitativo, os modelos com base na significância dos coeficientes de regressão, através do teste t a $10 \%$ de probabilidade, no coeficiente de determinação $\left(\mathrm{R}^{2}\right)$ e no fenômeno biológico. Para execução das análises estatísticas se usou o programa estatístico SAEG (2006).

\section{RESULTADOS E DISCUSSÃO}

Os valores médios mensais dos elementos meteorológicos obtidos durante o período estudado, são apresentados na Figura 1. Os valores médios mensais de radiação solar apresentaram grandes oscilações durante o período experimental e variaram de 738 a $1.103 \mathrm{~W} \mathrm{~m}^{-2}$, nos períodos seco (entre abril e setembro) e chuvoso (entre outubro e março), respectivamente, comportamento este que influenciou os valores de temperatura e, conseqüentemente, os de evapotranspiração de referência (ETo). Os valores médios mensais de temperatura durante o experimento variaram de 18,7 a $25,6{ }^{\circ} \mathrm{C}$, sendo máximos entre os meses de outubro e março e mínimos entre os meses de abril e setembro. Os valores médios mensais de ETo durante o estudo variaram de 1,92 a 4,98 $\mathrm{mm} \mathrm{dia}^{-1}$, sendo mínimos em maio de 2004 e máximos em outubro de 2003. Os valores médios mensais de umidade relativa variaram entre 69 a 97\%. O comportamento da umidade relativa foi o oposto da radiação solar e da temperatura, obser vando-se valores máximos entre os meses de dezembro e maio e mínimos entre os meses de junho e novembro.

Observou-se que o efeito proporcionado pelas diferentes gramíneas na produtividade de MS passível de ser consumida pelos animais, foi dependente da lâmina de irrigação e da estação do ano (Tabela 2). Na estação outono/inverno, para a lâmina de irrigação de $45 \%$ da referência $(252 \mathrm{~mm})$, a maior $(\mathrm{p}<0,05)$ produtividade de MS foi verificada no capim-xaraés e as menores ( $p<0,05)$ nos capins Mombaça e Marandu; nas demais lâminas de irrigação não se verificou diferença $(p<0,05)$. Na estação primavera/verão e na lâmina de irrigação de $18 \%$ da referência $(101 \mathrm{~mm})$, não 


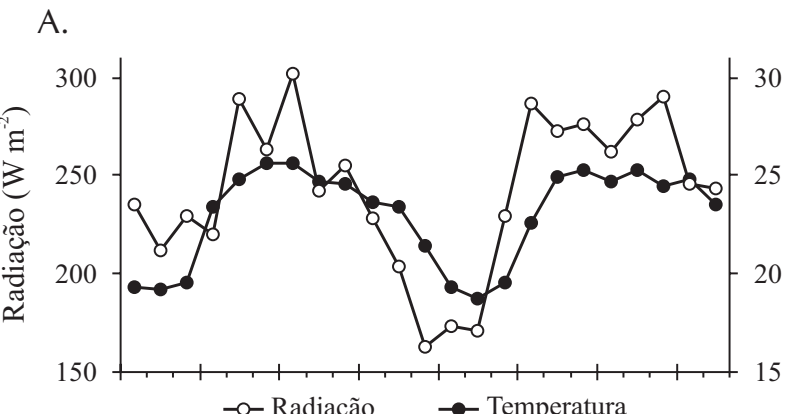

B.

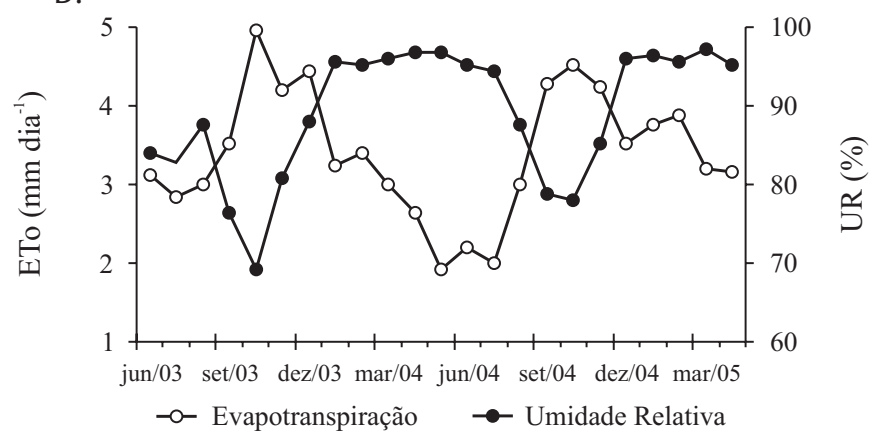

Figura 1. Média mensal dos dados climáticos no período de junho de 2003 a abril de 2005: (A) radiação solar $\left(\mathrm{W} \mathrm{m}^{-2}\right)$ e temperatura $\left({ }^{\circ} \mathrm{C}\right)$ e (B) evapotranspiração de referência $\left(\mathrm{mm} \mathrm{dia}^{-1}\right)$ e umidade relativa $(\%)$

se constatou diferença ( $\mathrm{p}>0,05)$ entre as gramíneas; nas demais lâminas ocorreu diferença $(\mathrm{p}<0,05)$, em que no geral o capim-xaraés se destacou por apresentar maior produtividade em relação às demais gramíneas.

A média da produtividade de MS dos capins Xaraés, Estrela, Marandu, Mombaça, Tanzânia e Pioneiro, foi de 13.940, $12.324,11.748,11.343,10.917$ e $10.900 \mathrm{~kg} \mathrm{ha}^{-1} \mathrm{ano}^{-1}$, respectivamente. Na literatura, o potencial produtivo dessas gramíneas, Pioneiro, Mombaça, Tanzânia, Xaraés e Estrela, é de 47, 33, 26, 21 e $20 \mathrm{t} \mathrm{ha}^{-1} \mathrm{ano}^{-1}$, respectivamente (Jank et al., 2005; Pedreira \& Tonato, 2006). Percebe-se que todas as produtividades de MS dos capins estudados permaneceram abaixo do potencial produtivo uma vez que, para a planta produzir o seu potencial, é conveniente que vários fatores responsáveis para o seu crescimento e desenvolvimento estejam em condições ótimas, como clima, adubação e umidade do solo, dentre outros; outra provável explicação seria o fato da matéria seca ter sido obtida pelo método de simulação de pastejo e, desta forma, apenas a forragem potencialmente consumível é considerada e então seu valor é subestimado, ao ser comparado com as produtividades potenciais que consideram toda a matéria seca (folhas e colmos); este evento é comprovado ao se analisar a produtividade de MS do capimpioneiro que foi demasiadamente baixa em relação ao seu potencial, cerca de apenas $25 \%$, enquanto as outras gramíneas produziram cerca de $50 \%$ do potencial. O capim-pioneiro possui crescimento rápido (Jank et al., 2005), o que faz alongar seu colmo; assim, maior quantidade de componente de produção (colmo) foi deixada no campo, o que contribuiu para uma produtividade menor .

Estabelecendo comparações entre os dois capins da espécie Brachiaria brizantha, Xaraés e Marandu, observou-se que, dentro de algumas lâminas de irrigação e estações do ano, não houve diferença $(\mathrm{p}>0,05)$ entre suas produtividades de MS, porém em "valor numérico" o capim-xaraés apresentou maior produtividade de MS em relação ao Marandu; este mesmo comportamento foi verificado por Rodrigues (2004), trabalhando com os mesmos capins no município de Planaltina, DF, em sistema irrigado, com dose nitrogenada de $75 \mathrm{~kg} \mathrm{ha}^{-1} \mathrm{ano}^{-1} \mathrm{e}$ intervalos de corte de 28 dias. Tais diferenças foram significativas $(\mathrm{p}<0,05)$ na lâmina de $45 \%$. A produtividade de MS no período de março a outubro de 2003 dos capins Xaraés e Marandu foi de 6.211 e $5.856 \mathrm{~kg} \mathrm{ha}^{-1} \mathrm{ano}^{-1}$, respectivamente, mas a diferença de $355 \mathrm{~kg}$ não foi significativa $(\mathrm{p}>0,05)$ pelo teste de Tukey.

Notou-se, independentemente das estações do ano e das distintas lâminas de irrigação, que as duas cultivares de $P a-$ nicum Tanzânia e Mombaça não diferiram entre si $(\mathrm{p}>0,05)$. Santos et al. (2003) verificaram, em seu trabalho sob irrigação, que os capins Tanzânia e Mombaça também não diferiram quanto à produtividade de MS; o trabalho foi realizado

Tabela 2. Valores médios de matéria seca passível de ser consumida (kg ha-1) sob condições de pastejo nas respectivas combinações de lâminas, gramíneas e estações do ano

\begin{tabular}{|c|c|c|c|c|c|c|}
\hline \multirow{2}{*}{ Gramínea } & \multicolumn{2}{|c|}{$0 \%$ (0 mm) } & \multicolumn{2}{|c|}{$18 \%$ (101 mm) } & \multicolumn{2}{|c|}{$45 \%$ (252 mm) } \\
\hline & Out./Inv. & Pri./Ver. & Out./Inv. & Pri./Ver. & Out./Inv. & Pri./Ver. \\
\hline Xaraés & $4.186 \pm 734 \mathrm{Ab}$ & $7.622 \pm 594 \mathrm{Aa}$ & $5.090 \pm 611 \mathrm{Ab}$ & $7.869 \pm 240 \mathrm{Aa}$ & $7.063 \pm 433 \mathrm{Aa}$ & $8.164 \pm 210 \mathrm{Aa}$ \\
\hline Mombaça & $3.718 \pm 663 \mathrm{Ab}$ & $6.535 \pm 500 \mathrm{ABa}$ & $4.366 \pm 14 \mathrm{Ab}$ & $6.227 \pm 77 \mathrm{Aa}$ & $4.620 \pm 19 \mathrm{Bb}$ & $7.494 \pm 692 \mathrm{ABa}$ \\
\hline Tanzânia & $3.585 \pm 472 \mathrm{Ab}$ & $6.385 \pm 809 \mathrm{ABa}$ & $3.987 \pm 214 \mathrm{Ab}$ & $6.272 \pm 774 \mathrm{Aa}$ & $5.082 \pm 83 \mathrm{ABb}$ & $6.716 \pm 736 \mathrm{ABa}$ \\
\hline Pioneiro & $4.202 \pm 695 \mathrm{Ab}$ & $7.543 \pm 424 \mathrm{Aa}$ & $4.962 \pm 200 \mathrm{Ab}$ & $6.854 \pm 482 \mathrm{Aa}$ & $5.419 \pm 522 \mathrm{ABb}$ & $6.915 \pm 450 \mathrm{ABa}$ \\
\hline Marandu & $4.065 \pm 183 \mathrm{Ab}$ & $6.794 \pm 109 \mathrm{ABa}$ & $4.154 \pm 673 \mathrm{Ab}$ & $6.481 \pm 52 \mathrm{Aa}$ & $4.805 \pm 726 \mathrm{Ba}$ & $5.754 \pm 855 \mathrm{Ba}$ \\
\hline Estrela & $4.333 \pm 283 \mathrm{Aa}$ & $5.443 \pm 869 \mathrm{Ba}$ & $4.358 \pm 796 \mathrm{Ab}$ & $7.612 \pm 621 \mathrm{Aa}$ & $6.150 \pm 505 \mathrm{ABa}$ & $7.229 \pm 608 \mathrm{ABa}$ \\
\hline \multirow{2}{*}{ Gramínea } & \multicolumn{2}{|c|}{$77 \%$ (431 mm) } & \multicolumn{2}{|c|}{$100 \%(560 \mathrm{~mm})$} & \multicolumn{2}{|c|}{$120 \%(672 \mathrm{~mm})$} \\
\hline & Out./Inv. & Pri./Ver. & Out./Inv. & Pri./Ver. & Out./Inv. & Pri./Ver. \\
\hline Xaraés & $6.269 \pm 314 \mathrm{Ab}$ & $8.504 \pm 321 \mathrm{Aa}$ & $6.870 \pm 158 \mathrm{Aa}$ & $7.413 \pm 694 \mathrm{ABa}$ & $6.352 \pm 451 \mathrm{Ab}$ & $8.237 \pm 645 \mathrm{Aa}$ \\
\hline Mombaça & $5.483 \pm 55 \mathrm{Aa}$ & $6.214 \pm 249 \mathrm{Ba}$ & $4.847 \pm 24 \mathrm{Ab}$ & $6.137 \pm 401 \mathrm{ABa}$ & $6.167 \pm 486 \mathrm{Aa}$ & $6.247 \pm 138 \mathrm{ABa}$ \\
\hline Tanzânia & $5.422 \pm 610 \mathrm{Aa}$ & $6.600 \pm 746 \mathrm{ABa}$ & $5.095 \pm 793 \mathrm{Aa}$ & $5.435 \pm 452 \mathrm{Ba}$ & $4.895 \pm 543 \mathrm{Aa}$ & $5.928 \pm 457 \mathrm{Ba}$ \\
\hline Pioneiro & $5.009 \pm 779 \mathrm{Ab}$ & $6.675 \pm 174 \mathrm{ABa}$ & $5.625 \pm 579 \mathrm{Aa}$ & $5.890 \pm 673 \mathrm{ABa}$ & $5.425 \pm 644 \mathrm{Aa}$ & $5.970 \pm 403 \mathrm{Ba}$ \\
\hline Marandu & $4.891 \pm 141 \mathrm{Ab}$ & $7.026 \pm 342 \mathrm{ABa}$ & $5.050 \pm 782 \mathrm{Aa}$ & $5.560 \pm 213 \mathrm{ABa}$ & $5.056 \pm 74 \mathrm{Aa}$ & $5.868 \pm 641 \mathrm{Ba}$ \\
\hline Estrela & $5.907 \pm 555 \mathrm{Ab}$ & $7.318 \pm 151 \mathrm{ABa}$ & $6.300 \pm 627 \mathrm{Ab}$ & $7.537 \pm 319 \mathrm{Aa}$ & $5.128 \pm 410 \mathrm{Ab}$ & $6.629 \pm 853 \mathrm{ABa}$ \\
\hline
\end{tabular}


no município de Recife, PE, utilizando-se adubação nitrogenada com $50 \mathrm{~kg} \mathrm{ha}^{-1} \mathrm{ano}^{-1}$ de N e $20 \mathrm{t} \mathrm{ha}^{-1} \mathrm{ano}^{-1}$ de esterco bovino com intervalo de cortes de 35 dias. Soares Filho et al. (2002), cultivando ambos os capins em sistema não-irrigado no município de Piacatu, SP , com adubação nitrogenada de $200 \mathrm{~kg} \mathrm{ha}^{-1}$ ano $^{-1}$ e intervalos de corte de 35 e 49 dias nas estações chuvosa e seca, respectivamente, também não constataram diferença de produtividade de MS entre os capins Tanzânia e Mombaça, porém esses mesmos autores encontraram maiores produtividade de MS (T anzânia $11.800 \mathrm{~kg} \mathrm{ha}^{-1} \mathrm{e}$ Mombaça $11.400 \mathrm{~kg} \mathrm{ha}^{-1}$ ) na estação chuvosa, em comparação com o presente trabalho, e menores produtividades de MS (Tanzânia $2.100 \mathrm{~kg} \mathrm{ha}^{-1}$ e Mombaça $1.600 \mathrm{~kg} \mathrm{ha}^{-1}$ ) na estação seca, em relação aos resultados deste trabalho. A produtividade de MS na estação seca foi de 18 e 14\% em relação à estação chuvosa, para os capins Tanzânia e Mombaça, respectivamente. No presente trabalho, esta mesma relação foi, em média, de $75 \%$, em ambos os capins, ante o que se pode comprovar que a irrigação ajuda a equilibrar a produção de MS entre as estações seca e chuvosa.

Verifica-se, ainda na Tabela 2, não apenas para os capins do gênero Panicum como relatado anteriormente, de que a produtividade de MS nos outros tratamentos também foi geral maiores $(\mathrm{p}<0,05)$ na estação primavera/verão em relação à estação outono/inverno; este resultado é decorrente do conjunto das condições como menores temperaturas e menores radiações observadas na estação outono/inverno (Figura 1A); desta forma, deu-se queda no metabolismo da planta, resultando em menores taxas de perfilhamento, de aparecimento de folhas e alongamento de folhas e colmo e, em conseqüência, menores taxas evapotranspirométricas. Salienta-se que a temperatura de inverno na região do município de Gover nador Valadares é maior que nas regiões em que foram desenvolvidos, no passado, trabalhos de pesquisa com irrigação de pastagem (V içosa, MG, Piracicaba, SP, e Triângulo Mineiro); com isto, é possível justificar a não-interferência da estação em alguns tratamentos. Nessas regiões se verifica expressiva produtividade de MS na estação primavera/ verão em relação ao período outono/inverno.

As lâminas de irrigação proporcionaram efeito $(\mathrm{p}<0,05)$ na produtividade de MS. As equações para estimativa da produtividade de MS para as gramíneas cultivadas na estação outono/inverno estão apresentadas na Figura 2; notou-se que a lâmina de irrigação proporcionou efeitos linear e positivo $(\mathrm{p}<0,05)$ nas gramíneas Mombaça, Pioneiro e Marandu, ou seja, o aumento da lâmina de irrigação ensejou aumento na produtividade de MS; nas demais gramíneas, Xaraés, Tanzânia e Estrela, foi notória a resposta quadrática $(\mathrm{p}<0,05)$, em que os máximos foram estimados nas lâminas de irrigação de $80 \%$ (450 mm), 80\% (447 mm) e 74\% da referência $(415 \mathrm{~mm})$, respectivamente. Smeal et al. (2005) avaliando oito gramíneas no período frio na região de Colorado (EUA), obtiveram resultados semelhantes ao presente trabalho; eles aplicaram lâminas de irrigação incluindo as precipitações entre $450 \mathrm{e}$ $1000 \mathrm{~mm} \mathrm{ano}^{-1}$ e observaram crescimento linear da produtividade de MS para todas as gramíneas estudadas. Lourenço (2004) avaliando o capim-tanzânia no município de Piracicaba, SP submetido a diferentes lâminas de irrigação e aduba- ção nitrogenada, observou que, independentemente da adubação nitrogenada, a produtividade de MS máxima ficou entre 75 e 100\% da lâmina de irrigação correspondente à evapotranspiração de referência, e ainda verificou que, quanto maior a dose nitrogenada mais significativo foi o efeito da deficiência hídrica na produção de forragem do capim-tanzânia, ou seja, quanto mais intensificado o sistema de produção maior a quebra de produtividade quando houver veranicos. Desta forma, o sistema de irrigação se torna um atrativo importante ao pecuarista, para que se possa evitar os riscos climáticos e garantir a produção.

Lopes et al. (2003) verificaram, avaliando o efeito da irrigação e adubação no município de Viçosa, MG, que esses fatores não foram suficientes para promover incrementos significativos na disponibilidade de matéria seca do capimelefante no período seco (outono/inverno) em razão principalmente das baixas temperaturas; os mesmos autores concluíram que a utilização da irrigação, apesar de não eliminar o efeito da estacionalidade de produção do capimelefante, permitiu uma antecipação do período de crescimento das plantas, quando a temperatura não foi limitante (primavera), ocasionando aumento significativo da disponibilidade de forragem ao longo do ano, além de assegurar a estabilidade da produção no verão.

Na estação primavera/verão (Figura 2) observou-se, com exceção do capim-pioneiro, que não houve efeito $(\mathrm{p}>0,05)$ de lâminas de irrigação na produtividade de MS. Também Pinheiro (2002), avaliando o capim-tanzânia no município de Piracicaba, SP, não observou resposta de MS quando submetido a distintas lâminas de irrigação, porém este mesmo autor relatou que a irrigação de pastagem é uma ferramenta complementar do pecuarista para otimizar a produção anual de MS na propriedade. Outro trabalho realizado no município de Piracicaba, SP, e em que não houve resposta da produtividade de MS à lâmina de irrigação, foi o de Cunha et al. (2004), também avaliando o capim-tanzânia. Em ambos os trabalhos, os autores atribuíram, à precipitação pluvial, o fator minimizador do efeito das lâminas de irrigação; além disso, a ausência de efeito na produtividade de MS pelo aumento da lâmina de irrigação pode ser justificada pelo acúmulo de nutrientes aplicados na estação outono/inverno nas parcelas em condições de menor umidade do solo, sendo depois disponibilizados na estação chuvosa (primavera/verão), mascarando o efeito proporcionado pelas lâminas; já com relação ao capim-pioneiro, verificou-se efeito linear negativo ( $\mathrm{p}<0,05)$, isto é, o aumento da lâmina de irrigação proporcionou queda na produtividade de MS, resultado que, possivelmente, pode ser justificado pelo mesmo motivo do acúmulo de nutrientes no período seco, pela disponibilização desses no período chuvoso e pela baixa resistência dessa gramínea ao excesso de umidade no solo, quando ocorreram precipitações logo após as irrigações. Este resultado é semelhante aos encontrados por Soria et al. (2003) no município de Picacicaba, SP , cujo aumento da lâmina de irrigação proporcionou redução na produtividade de MS do capim-tanzânia. Essas constatações também podem ser um indicativo de maior tolerância desses capins à deficiência hídrica, o que sugere a necessidade da realização de outros trabalhos em tais condições. 

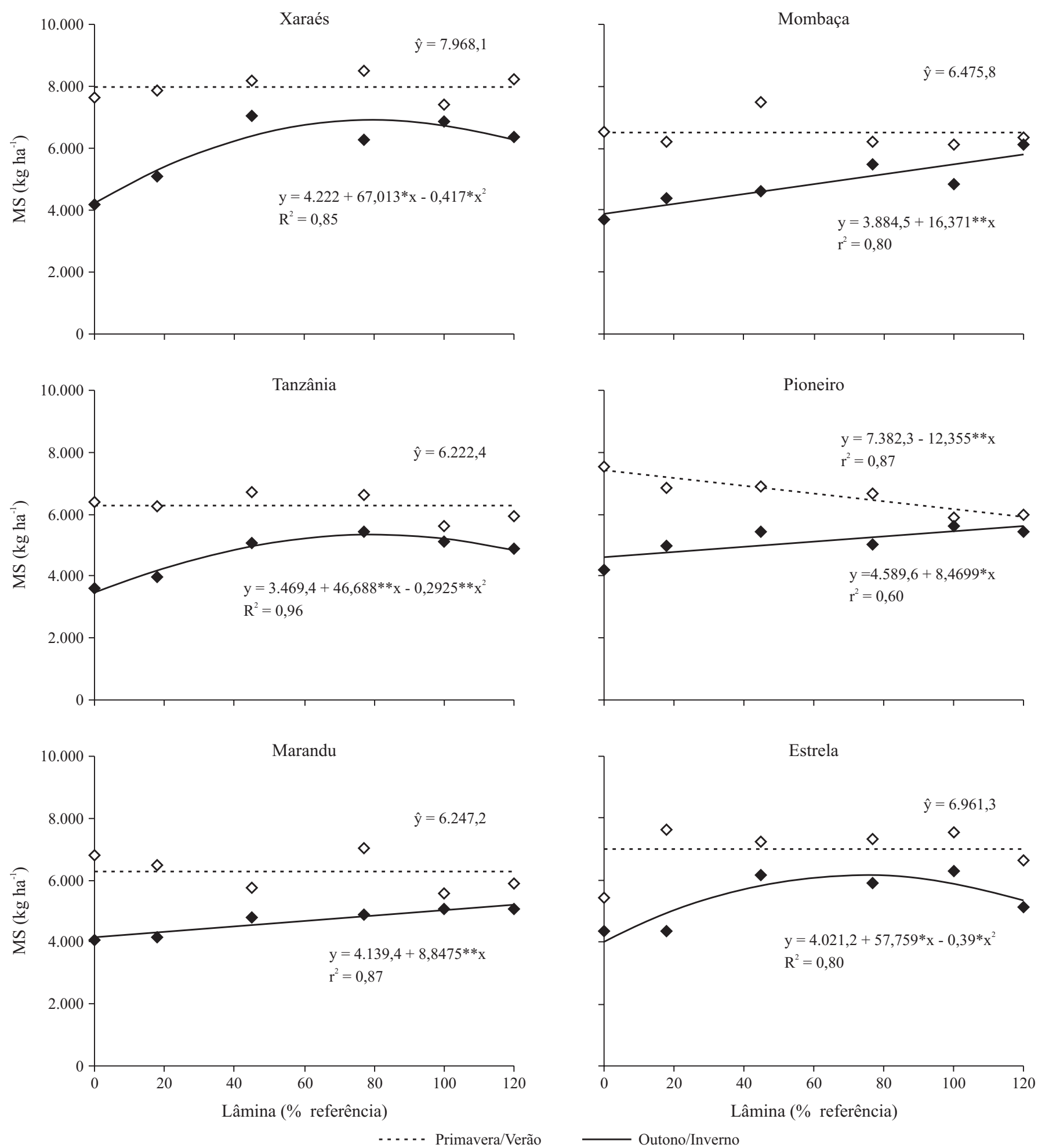

${ }^{*} e^{* *}$ significativo a 5 e $1 \%$ de probabilidade, respectivamente

- . . . . - Primavera/Verão

Figura 2. Estimativa da produtividade de matéria seca passível de ser consumida ( $\left.\mathrm{kg} \mathrm{ha}^{-1}\right)$ de seis gramíneas forrageiras sob condições de pastejo, em função das lâminas de irrigação (\% referência) nos períodos de Primavera/Verão e Outono/Inverno

\section{CONCLUSÕES}

1. O capim-xaraés possui maior produtividade de matéria seca.

2. A estação primavera/verão proporciona maior produtividade de matéria seca, representando entre 55 e $67 \%$ da pro- dução total na lâmina de irrigação de $100 \%$ da referência.

3. A irrigação proporciona maior equilíbrio na produtividade de matéria seca entre as estações outono/inverno e primavera/verão.

4. As lâminas de irrigação aumentam a produtividade de matéria seca das gramíneas na estação outono/inverno. Reco- 
mendam-se as lâminas de irrigação de 120, 120, 120, 80, 80 e 74\% da lâmina de referência, para as gramíneas Mombaça, Pioneiro, Marandu, Xaraés, Tanzânia e Estrela, respectivamente.

\section{LITERATURA CITADA}

Aroeira, L. J. M.; Lopes, F. C. F.; Deresz, F.; Verneuqe, R. S.; Dayrell, M. S.; Matos, L. L.; Maldonado Vasquez, H.; Vittori, A. Pasture availability and dry matter intake of lactating crossbred cows grazing elephant grass (Pennisetum purpureum, Schum). Animal Feed Science and Technology, v.78, n.3, p.313-324, 1999.

CFSEMG - Comissão de Fertilidade do Solo do Estado de Minas Gerais. Recomendações para o uso de corretivos e fertilizantes em Minas Gerais: $5^{a}$ aproximação. 20.ed. Viçosa: UFV, 1999. 359p.

Cunha, C. A. H.; Ângulo Filho, R.; Coelho, R. D. Avaliação do comportamento espectral e da produtividade de matéria seca em capim-tanzânia (Panicum maximum Jacq. cv. Tanzânia). Engenharia Rural, v.15, n.1, p.23-30, 2004.

Cunha, F. F.; Soares, A. A.; Pereira, O. G.; Lambertucci, D. M.; Abreu, F. V. S. Características morfogênicas e perfilhamento do Panicum maximum Jacq. cv. Tanzânia irrigado. Ciência e Agrotecnologia, v.31, n.3, p.628-635, 2007.

EMBRAPA - Empresa Brasileira de Pesquisa Agropecuária. Manual de métodos de análise de solo. 2.ed. Rio de Janeiro: Embrapa-CNPS, 1997. 212p.

Fernandes, A. M.; Queiroz, A. C.; Pereira, J. C.; Lana, R. P.; Barbosa, M. H. P.; Fonseca, D. M.; Detmann, E.; Cabral, L. S.; Pereira, E. S.; Vittori, A. Composição químico-bromatológica de variedades de cana-de-açúcar (Saccharum spp L.) com diferentes ciclos de produção (precoce e intermediário) em três idades de corte. Revista Brasileira de Zootecnia, v.32, n.4, p.977-985, 2003.

Goh, K. M.; Bruce, G. E. Comparison of biomass production and biological nitrogen fixation of multi-species pastures (mixed herb leys) with perennial ryegrass-white clover pasture with and without irrigation in Canterbury, New Zealand. Agriculture, Ecosystems and Environment, v.110, n.3, p.230-240, 2005.

Hanks, R. J.; Keller, J.; Rasmussen, V. P.; Wilson, G. D. Line source sprinkler for continuous variable irrigation crop production studies. Soil Science of American Journal, v.40, n.3, p.426-429, 1976.

Jank, L.; Valle, C. B.; Karia, C. T.; Pereira, A. V.; Batista, L. A. R.; Resende, R. M. S. Opções de novas cultivares de gramíneas e leguminosas forrageiras tropicais para Minas Gerais. Informe Agropecuário, v.28, n.226, p.26-35, 2005.

Lopes, R. S.; Fonseca, D. M.; Oliveira, R. A.; Nascimento Jr., D.; Andrade, A. C.; Stock, L. A.; Martins, C. E. Disponibilidade de matéria seca em pastagens de capim-elefante irrigadas. Ciência e Agrotecnologia, v.27, n.6, p.1388-1394, 2003.
Lourenço, L. F. Avaliação da produção de capim-tanzânia em ambiente protegido sob disponibilidade variável de água e nitrogênio no solo. Piracicaba: ESALQ, 2004. 77p. Dissertação Mestrado

Mistura, C.; Fagundes, J. L.; Fonseca, D. M.; Moreira, L. M.; Vitor, C. M. T.; Nascimento Jr., D.; Ribeiro Jr., J.I. Disponibilidade e qualidade do capim-elefante com e sem irrigação adubado com nitrogênio e potássio na estação seca. Revista Brasileira de Zootecnia, v.35, n.2, p.372-379, 2006.

Palieraqui, J. G. B.; Fontes, C. A. A.; Ribeiro, E. G.; Cóser, A. C.; Martins, C. E.; Fernandes, A. M. Influência da irrigação sobre a disponibilidade, a composição química, a digestibilidade e o consumo dos capins Mombaça e Napier. Revista Brasileira de Zootecnia, v.35, n.6, p.2381-2387, 2006.

Pedreira, C. G. S.; Tonato, F. Bases ecofisiológicas para manejo de gramíneas do gênero Cynodon. In: Simpósio de Forragicultura, 3, 2006, Viçosa. Anais... Viçosa: UFV, 2006. p.93-115.

Pinheiro, V. D. Viabilidade econômica da irrigação de pastagem de capim-tanzânia em diferentes regiões do Brasil. Piracicaba: ESALQ, 2002. 85p. Dissertação Mestrado

Rassini, J. R. Manejo de água de irrigação para alfafa (Medicago sativa L.). Revista Brasileira de Zootecnia, v.30, n.6, p.1681-1688, 2001.

Richards, L. A. Methods of measuring soil moisture tension. Soil Science of American Journal, v.68, n.1, p.95-112, 1949.

Rodrigues, D. C. Produção de forragem de cultivares de Brachiaria brizantha (Hochst. Ex A. Rich.) Stapf e modelagem de respostas produtivas em função de variáveis climáticas. Piracicaba: ESALQ, 2004. 94p. Dissertação Mestrado

SAEG - Sistema para Análises Estatísticas, Versão 9.0. Viçosa: Fundação Arthur Bernardes/UFV. 2006.

Santos, M. V. F.; Dubeux Jr., J. C. B.; Silva, M. C.; Santos, S. F.; Ferreira, R. L. C.; Mello, A. C. L.; Farias, I.; Freitas, E.V. Produtividade e composição química de gramíneas tropicais na zona da mata de Pernambuco. Revista Brasileira de Zootecnia, v.32, n.4, p.821-827, 2003.

Smeal, D.; O’Neill, M. K.; Arnold, R. N. Forage production of cool season pasture grasses as related to irrigation. Agricultural Water Management, v.76, n.3, p.224-236, 2005.

Soares Filho, C. V.; Rodrigues, L. R. A.; Perri, S. H. V. Produção e valor nutritivo de dez gramíneas forrageiras na região noroeste do Estado de São Paulo. Acta Scientiarum Agronomy, v.24, n.5, p.1377-1384, 2002.

Soria, L. G. T.; Coelho, R. D.; Herling, V. R.; Pinheiro, V. Resposta do capim-tanzânia a aplicação do nitrogênio e de lâminas de irrigação. I: Produção de forragem. Revista Brasileira de Engenharia Agrícola e Ambiental, v.7, n.3, p.430-436, 2003.

Teodoro, R. E. F.; Aquino, T. P.; Chagas, L. A. C.; Mendonça, F. C. Irrigação na produção do capim Panicum maximum cv. Tanzânia. Bioscience Journal, v.18, n.1, p.13-21, 2002. 